\title{
Pharmacological treatment of negative symptoms in schizophrenia: update and proposal of a clinical algorithm
}

This article was published in the following Dove Press journal:

Neuropsychiatric Disease and Treatment

\author{
Giancarlo Cerveri' \\ Camilla Gesi \\ Claudio Mencacci ${ }^{2}$ \\ 'Mental Health Department, ASST Lodi, \\ Lodi, Italy; ${ }^{2}$ Mental Health Department, \\ ASST Fatebenefratelli-Sacco, Milan, Italy
}

Correspondence: Giancarlo Cerveri Mental Health Department, ASST Lodi, Lodi 26900 , Italy

Tel +39347235382I

Email Giancarlo.cerveri@gmail.com

\begin{abstract}
The clinical presentation of schizophrenia encompasses symptoms divided into three dimensions: positive, negative, and cognitive. Negative symptoms (NS), in particular, have a major impact on the quality of life of the affected subject, and, differing from positive symptoms, are often associated with a limited response to pharmacotherapy. To date, studies specifically investigating NS in schizophrenia are scant; therefore, proper selection of therapy for NS remains a major unmet medical need. Given the heterogeneity of the clinical presentation of schizophrenia, the treatment of NS, as well as therapy for other associated symptoms, should be largely individualized according to a patient's specific characteristics. In this paper, we review current knowledge on NS and construct a clinical algorithm for the treatment of schizophrenic conditions with pronounced NS. Overall, data from the literature suggest that second-generation antipsychotics, such as cariprazine and amisulpride, should be preferred over first-generation antipsychotics (FGAs), as they are associated with better functional outcomes and lower cognitive impairment. The combination of antipsychotics and antidepressants may also improve NS while addressing some affective disorders associated with schizophrenia; however, no clear information is available on the effects of this combination on primary NS or on the mechanism of action of the combination. In the proposed clinical algorithm, we suggest that cariprazine should be used as first-line treatment for patients with predominant NS, and that amisulpride should be considered as an alternative in cases of cariprazine failure. Further treatment lines may include the use of olanzapine and quetiapine, and add-on therapy with antidepressants.
\end{abstract}

Keywords: cariprazine, mental disorders, symptoms

\section{Introduction}

The clinical presentation of schizophrenia encompasses symptoms divided into three dimensions: positive, negative, and cognitive. Schizophrenia positive symptoms include psychotic manifestations, such as hallucinations and delusions. Schizophrenia negative symptoms (NS) include loss of thoughts and/or altered behaviors, lack of motivation, blunted affect, severe social withdrawal, and paucity of speech and communication. Lastly, cognitive symptoms are disorders of memory and attention, and executive functioning disorders. ${ }^{1}$

In particular, NS have a major impact on the quality of life of the affected subject ${ }^{2,3}$ and, differing from positive symptoms, are often associated with a limited response to pharmacotherapy. ${ }^{4-6}$ To date, studies specifically investigating NS in schizophrenia are scant. ${ }^{5}$ Therefore, proper selection of therapy of NS remains 
a major unmet medical need, and the importance of studying NS has been advocated by both the European Medicines Agency (EMA) and the US Food and Drug Administration (FDA), which have endorsed the specific investigation of NS in the development of antipsychotic drugs. ${ }^{7}$ Importantly, given the heterogeneity of the clinical presentation of schizophrenia, the treatment of NS, as well as therapy for other associated symptoms, should be largely individualized according to a patient's specific characteristics. $^{8,9}$

The objectives of the present paper are to review current knowledge on NS and to construct a clinical algorithm for the treatment of schizophrenic conditions with pronounced NS.

\section{NS in schizophrenia: history of definitions and nosographical relevance}

NS have been classically described as the clinical core of schizophrenia, with even greater relevance than positive features of the disorder. Jackson, in 1885, defined NS as "reductions in aspects of higher cognitive and emotional functioning", and considered positive symptoms as "release phenomena, episodic distortions or exaggerations in normal function". ${ }^{10}$ Kraepelin, in 1919, conceptualized NS as a "weakening of those emotional activities that permanently form the mainsprings of volition, emotional dullness, failure of mental activities, loss of mastery over volition of ability for independent action", 11 while Bleuler, in 1950, considered "affective blunting" and "emotional withdrawal" as "fundamental" to defining schizophrenia, as opposed to hallucinations, delusions, and catatonia, which only characterize the acute exacerbation. ${ }^{12}$ Notwithstanding the importance of NS for the construct of schizophrenia, since the 1950s the introduction of effective pharmacological treatments for positive symptoms has slowly shifted the diagnostic process toward a positive symptom-based paradigm. ${ }^{13,14}$ This change in focus has been evident since the third edition of the Diagnostic and Statistical Manual of Mental Disorders (DSM III), ${ }^{15}$ in which the diagnosis of schizophrenia was mainly based on Schneider's first-rank symptoms. ${ }^{16}$ Yet, some research continued to devote interest to NS, albeit in the shade of positive manifestations. During the $1980 \mathrm{~s}$, a number of classifications of schizophrenia based on NS were proposed, ${ }^{17,18}$ which showed, however, several limitations, including the lack of diagnostic stability over time and the poor prognostic value. ${ }^{19}$ Over the past few decades, the effort to define relevant schizophrenic phenotypes based on NS comprised the dissection of deficit schizophrenia, ${ }^{20}$ which refers to patients in whom NS are trait-like, persistent, and idiopathic. ${ }^{21,22}$ As several editions of the two main classification systems of mental diseases, the $\mathrm{DSM}^{23}$ and the International Statistical Classification of Diseases and Related Health Problems (ICD), ${ }^{24}$ allowed the diagnosis of schizophrenia to be made even in the absence of NS, the accumulating evidence concerning the impact of NS on real-life functioning, as well as the urge to develop new treatments targeting these symptoms, renewed interest in NS conceptualization ${ }^{25-27}$ and raised once again the need to offer discrete subtypes of schizophrenia to be used in research.

Within the broad debate about which dimensions should be included in NS, the US National Institute of Mental Health (NIMH), in the framework of the Measurement and Treatment Research to Improve Cognition in Schizophrenia (MATRICS) initiative, held a Consensus Development Conference that proposed five domains of NS, organized in a two-factor structure: the expressivity factor, including blunted affect and alogia, and a factor combining avolition, anhedonia, and asociality. $^{3}$ The Brief Negative Symptom Scale (BNSS), ${ }^{28}$ which grew out of the conference's recommendations, was shown to reflect the same two domains as part of the construct of NS (Table 1). These dimensions play a particularly important role in differentiating patients with schizophrenia from a clinical viewpoint, but there is no clear evidence that they can define discrete subtypes of illness, rather than a continuous distribution of NS that contributes to the substantial heterogeneity of schizophrenia in terms of multiple dimensions. ${ }^{19,29}$ However, it has been hypothesized that treatment-responsive schizophrenia may be categorically distinct from treatment-resistant schizophrenia, the latter being, in turn, correlated with high levels of $\mathrm{NS}^{30,31}$ Several studies indicate that NS relate to worse symptomatic outcomes, continuous illness course, poorer global functioning, and lower likelihood of achieving recovery and clinical remission in the long term, ${ }^{32,33}$ ultimately suggesting that the unmet therapeutic challenge of NS may be crucial for the long-term outcome of schizophrenia. Importantly, along with recent data, NS represent the best symptomatic predictor of functioning, both crosssectionally and longitudinally, in subjects with their first episode of psychosis. ${ }^{34,35}$ In keeping with other early psychosis and mixed chronicity studies, ${ }^{36,37}$ a 2019 study 
Table I Subscales in the Brief Negative Symptom Scale

\begin{tabular}{|l|l|l|l|}
\hline Subscale & Item & $\begin{array}{l}\text { AAA } \\
\text { factor }\end{array}$ & $\begin{array}{l}\text { EXP } \\
\text { factor }\end{array}$ \\
\hline Anhedonia & $\begin{array}{l}\text { Intensity of pleasure } \\
\text { Frequency of pleasurable } \\
\text { activities } \\
\text { Intensity of expected } \\
\text { pleasure }\end{array}$ & $\checkmark$ & $\checkmark$ \\
Lack of normal & Lack of normal distress & & \\
\hline Asstress & $\begin{array}{l}\text { Asociality: behavior } \\
\text { Asociality: internal } \\
\text { experience }\end{array}$ & $\checkmark$ & \\
\hline Avolition & $\begin{array}{l}\text { Avolition: behavior } \\
\text { Avolition: internal } \\
\text { experience }\end{array}$ & $\checkmark$ & \\
\hline Blunted affect & $\begin{array}{l}\text { Facial expression } \\
\text { Vocal expression } \\
\text { Expressive gestures }\end{array}$ & & $\checkmark$ \\
\hline Quantity of speech & & $\checkmark$ \\
\hline
\end{tabular}

Notes: Data from Kirkpatrick et al. ${ }^{28}$ a Lack of normal distress usually does not load strongly onto either factor.

Abbreviations: AAA, anhedonia/asociality/avolition; EXP, expressivity.

conducted among 638 children with early-onset psychosis in their first episode showed a significant association between NS and multiple antipsychotic treatment failure over a period of 5 years, after controlling for a number of confounders. ${ }^{38}$ Based on the relative fluctuation of NS in the first episode of psychosis and their increasing stability after the first year, ${ }^{39}$ targeting the negative dimension in this period may be even more important to prevent disability and maximize functional outcome. ${ }^{35,40}$

\section{Current classification of NS}

\section{Primary and secondary NS}

Most literature has classically distinguished between primary and secondary NS. While primary NS are considered to be intrinsic to schizophrenia, secondary NS are thought to depend on other factors, such as suspicious withdrawal or other positive psychotic symptoms, extrapyramidal side effects, depression, substance abuse, and mental retardation. ${ }^{41}$ The distinction between primary and secondary causation of NS has the potential to inform clinicians and to enable them to find the most adequate treatment for NS. ${ }^{42}$ However, from a clinical viewpoint, it may prove to be more difficult than expected: while concurrent substance abuse or mental retardation can be easily confirmed by gathering additional information, ascertaining the degree to which positive symptoms contribute to NS and ruling out concurrent depression may be challenging. Moreover, secondary NS may persist beyond the treatment of the suspected underlying cause, making it difficult to determine whether they would be better reconsidered as primary, primary with a superimposed secondary component, or treatment resistant.

Starting from the distinction between primary and secondary NS, some researchers hypothesized that schizophrenic patients who have persistent, primary NS may comprise a discrete subtype of schizophrenia, with distinctive clinical characteristics, long-term course, and biological correlates, termed deficit schizophrenia. ${ }^{29,43,44}$ The defining criteria of deficit schizophrenia include the presence of at least two from a list of five NS, persisting for at least 12 months and not depending on other factors. As long as they represent direct manifestations of schizophrenia, NS that characterize deficit schizophrenia are thought to be trait like, long lasting, and idiopathic. ${ }^{20,21}$ Despite several studies highlighting the distinctiveness of deficit schizophrenia, ${ }^{44,45}$ its dissection from other forms of schizophrenia may be difficult in everyday clinical practice and, as long as it depends on the distinction between primary and secondary NS, it may result in poor reliability, as mentioned in the above paragraph.

\section{Persistent NS}

The definition of persistent NS was scientifically developed to easily and reliably identify a quite homogeneous population of schizophrenic patients to be enrolled in clinical trials. ${ }^{3,46}$ Persistent NS are defined by the long-term persistence of moderate to severe NS, independent from acute exacerbation of positive symptoms, and deserving clinical attention and therapeutic intervention. Similarly to the deficit schizophrenia subgroup, patients with persistent NS demonstrate low levels of positive, affective, and extrapyramidal symptoms. ${ }^{46}$ Consistently, premorbid deficits and cognitive impairments are generally greater in deficit schizophrenia and persistent NS subgroups than in the transient subgroup. ${ }^{20,40,47}$ On the other hand, the group of subjects with persistent NS represents a broader population than those with deficit schizophrenia or primary NS, given that it includes both primary NS and secondary NS, which responded poorly or did not respond to interventions targeting the causes of secondary NS. ${ }^{46}$ An established definition 
of persistent negative type of schizophrenia is characterized by 1) a clinically stable and well-determined negative syndrome for 3 months prior to the psychiatric evaluation; 2) a score $\geq 24$ on the negative syndrome subscale of the Positive and Negative Syndrome Scale (PANSS); ${ }^{48}$ and 3) a score $\leq 4$ on the following PANSS items: excitement, hyperactivity, hostility, suspiciousness, uncooperativeness, and poor impulse control. Although it has been proposed that the definition of persistent NS, despite not distinguishing between primary and secondary NS, may be profitably used in clinical trials where sources of secondary NS are controlled for, only a few trials have used this definition as an inclusion criterion. ${ }^{49}$

\section{Prominent and predominant NS}

Despite the need for consensus on how to consistently define NS in clinical trials having been stressed, ${ }^{3,46}$ inclusion criteria are substantially different among studies. Stauffer et $\mathrm{al}^{50}$ classified patients with prominent NS as those having a PANSS negative score of $\geq 4$ on at least three items, or $\geq 5$ on at least two items; while patients with predominant NS were defined as a subset of subjects with prominent NS but with a lesser contribution of positive symptoms to overall disease severity, namely a PANSS positive score of b19, a Barnes Akathisia score of b2, a Simpson-Angus score of b4, and a Calgary Depressive Scale score of b9. In another trial, Alphs et al ${ }^{51}$ classified patients with predominant primary NS as those who did not reach a score $\geq 4$ on two or more items of the PANSS positive subscale.

The differences in the definition of prominent and predominant NS reflect, at least in part, the lack of agreement between regulatory agencies on the definition of NS for its use in pharmacological trials. The FDA requires that NS are "prominent", which means that patients only have a "high level" of NS, while the EMA includes the additional criterion of "no-to-little positive symptoms", which comprises the definition of "predominant" NS. ${ }^{52}$ In 2018, Krause et al published the first systematic review and meta-analysis regarding the effects of antipsychotics in people with schizophrenia and NS. ${ }^{53}$ Given the lack of a shared criterion defining NS, the main findings were presented separated on the basis of the distinction between prominent and predominant NS. Importantly, the authors pointed out that in several studies with prominent NS the effect sizes for positive symptoms were either identical to or higher than those for NS, rendering the possibility of confounding by secondary effects more likely. Consistently, possible confounding due to parallel effects on depression, positive symptoms, or extrapyramidal symptoms occurred more frequently in the studies conducted in patients with prominent NS, suggesting that the inclusion criterion of predominant NS probably provides a better safeguard against secondary effects than the criterion of prominent NS. Notably, besides reducing the risk of confounding secondary effects, the definition of predominant NS also provides further advantages: 1) it is clinically reliable, given that it does not imply a causative distinction between primary and secondary NS, but only requires that NS are pivotal and long-lasting; 2) although often overlapping with primary NS, it may actually include subtle secondary NS that persisted beyond the treatment of potential secondary causes and that may contribute to the clinical picture (eg, NS induced by antipsychotic and concurrent depression), providing a framework closer to realworld clinical practice; and 3) it broadly overlaps with the definition of persistent NS, recommended by the NIMHMATRICS Consensus Statement on Negative Symptoms. ${ }^{3}$

For the reasons mentioned in the previous paragraph, we mainly focus on studies reporting on the pharmacological treatment of predominant NS. However, significant data from studies using a less stringent definition of NS were also included. Moreover, given the greater robustness of their findings, data provided by meta-analyses were preferred, when available. A summary of the main findings of each pharmacological treatment is presented in Table 2.

\section{Pharmacological treatment of NS Antipsychotics}

Antipsychotic agents are currently the mainstay treatment for schizophrenia. ${ }^{54}$ According to several reviews, FGAs may affect functional outcomes by inducing neuromotor disorders, as well as by worsening NS, social withdrawal, and cognitive dysfunction. $^{55}$ Even though the greater efficacy on NS, claimed to be a core characteristic of second-generation antipsychotics (SGAs), has not always been confirmed, there is a common notion that SGAs should be preferred over FGAs when NS are prominent. $^{56} \mathrm{~A}$ meta-analysis published in $2009^{56}$ analyzed a total of 150 double-blind studies comparing FGAs and SGAs with 21,533 participants overall. Four SGAs (amisulpride, clozapine, olanzapine, and risperidone) were more efficacious than FGAs for the treatment of positive symptoms and NS. The other five SGAs (aripiprazole, quetiapine, sertindol, ziprasidone, and zotepine) were only as efficacious as FGAs, even in terms of NS. It is worth noting that the most efficacious drugs were better in terms of both positive symptoms and NS, casting doubts on the primary efficacy on 
Table 2 Summary of the main characteristics of medications on schizophrenia NS

\begin{tabular}{|c|c|c|}
\hline \multicolumn{2}{|l|}{ Drug class } & \multirow{2}{*}{$\begin{array}{l}\text { Main characteristics in NS } \\
\text { - May affect patients' functional outcomes } \\
\text { by inducing neuromotor disorders, wor- } \\
\text { sening NS, social withdrawal, and cogni- } \\
\text { tive dysfunction }\end{array}$} \\
\hline Antipsychotics & FGA & \\
\hline & SGA & $\begin{array}{l}\text { - More efficacious (amisulpride, clozapine, } \\
\text { olanzapine, and risperidone) than or as } \\
\text { efficacious (aripiprazole, quetiapine, ser- } \\
\text { tindol, ziprasidone, and zotepine) as FGA } \\
\text { in the treatment of PS and NS, with often } \\
\text { larger effect size on NS than PS } \\
\text { - Associated with lower cognitive impair- } \\
\text { ment and better functional outcomes } \\
\text { - Amisulpride } \\
\text { - Effective on predominant NS } \\
\text { Combined antidepressant effect that may } \\
\text { Cariprazine } \\
\text { - More effective than risperidone in redu- } \\
\text { cing specifically NS (no effect on depres- } \\
\text { sion and PS) } \\
\text { - Superior results compared with risperi- } \\
\text { done in real-world outcomes (personal } \\
\text { and social performance and quality- } \\
\text { adjusted life-years) } \\
\text { Olanzapine } \\
\text { - More effective than haloperidol in redu- } \\
\text { cing NS } \\
\text { Quetiapine } \\
\text { cing NS, but not PS }\end{array}$ \\
\hline \multicolumn{2}{|c|}{$\begin{array}{l}\text { Antidepressants } \\
\text { (add-on) }\end{array}$} & $\begin{array}{l}\text { - May improve NS and some affective dis- } \\
\text { orders associated with schizophrenia } \\
\text { - The mechanism of action is still to be } \\
\text { clarified } \\
\text { Fluoxetine, paroxetine, seligiline, } \\
\text { citalopram, reboxetine, fluvoxa- } \\
\text { mine, and mirtazapine } \\
\text { - Effective in reducing NS in patients with } \\
\text { predominant NS } \\
\text { - Lower effect size on depressive symp- } \\
\text { toms, possible independent action on NS } \\
\text { Amitriptyline, mianserin hydro- } \\
\text { chloride, trazodone hydrochloride, } \\
\text { paroxetine, } \\
\text { fluoxetine, or fluvoxamine } \\
\text { - Medium to high effect size in reducing } \\
\text { core NS in patients with mainly NS }\end{array}$ \\
\hline
\end{tabular}

Abbreviations: FGA, first-generation antipsychotic; SGA, second-generation antipsychotic; NS, negative symptoms; PS, positive symptoms.
NS, and suggesting that the improvement in NS may actually depend on the improvement in positive symptoms. ${ }^{56}$ However, the effect sizes for NS were often larger than those for positive symptoms, which may corroborate a direct effect of SGAs on NS. ${ }^{56}$ In addition, the efficacy of each SGA on depression was not consistent with that on NS (eg, risperidone did not seem to be better than FGAs, whereas aripiprazole and quetiapine were), providing a safeguard against the overlap between the effect on NS and that on depression. ${ }^{56}$ On the other hand, the majority of studies lasted only up to 12 weeks and were heterogeneous with regard to the phase of the disorder (acute versus chronic phase). Still, the use of SGAs appears to be associated with lower cognitive impairment than that of FGAs and with better functional outcomes. For these reasons, SGAs should be generally preferred in the treatment of schizophrenia with prominent NS. ${ }^{55}$ Likewise, when a treatment with FGAs is already in place, switching to a SGA may be a reasonable choice.

Amisulpride has been extensively investigated for the treatment of NS. ${ }^{57-60}$ Findings from a meta-analysis of placebo-controlled trials testing the efficacy of antipsychotics and involving a total of 590 participants treated with amisulpride, showed that amisulpride is significantly more efficacious than placebo in patients with predominant NS. ${ }^{57}$ The efficacy of amisulpride may be explained in the light of previous studies suggesting that hypodopaminergic tone in the prefrontal cortex may underlie the pathophysiology of NS and considering that amisulpride at low doses (the target dose of studies included in the meta-analysis ranged from 50 to $300 \mathrm{mg} /$ day) binds to presynaptic receptors in the frontal cortex, thus enhancing dopamine transmission in this area. ${ }^{57}$ On the other hand, the results of the meta-analysis also showed a significant effect of amisulpride on depressive symptoms. From this perspective, the effect of amisulpride could be also interpreted in the light of the known antidepressant effect of the drug, ${ }^{61}$ which may act on NS through an effect on secondary (depressive) NS rather than primary NS.

Cariprazine is an antipsychotic drug approved by both the EMA and the FDA for the treatment of schizophrenia. ${ }^{62}$ It is a partial agonist of the dopamine receptors $\mathrm{D}_{2} / \mathrm{D}_{3}$, with a 10 fold affinity for the $\mathrm{D}_{3}$ receptor, and also presents partial agonism for the serotonin (5-hydroxytryptamine) $5 \mathrm{HT}_{1 \mathrm{~A}}$ receptor, as well as antagonism at $5 \mathrm{HT}_{2 \mathrm{~B}}$ and $5 \mathrm{HT}_{2 \mathrm{~A}}$ receptors and for the histamine $\mathrm{H}_{1}$ receptor. ${ }^{63}$ These properties may suggest the efficacy of cariprazine in the treatment of NS. ${ }^{62}$ 
Cariprazine has demonstrated promising effectiveness in the treatment of NS, as it was shown to lead to greater reduction in NS than risperidone in a large trial enrolling 460 subjects with predominant $\mathrm{NS}^{7}$ In addition, cariprazine induced greater improvements in personal and social performance than risperidone. The findings were especially sound giving that there was virtually no effect on either depressive symptoms or positive symptoms, and that no differential change in extrapyramidal side effects was shown between the two antipsychotics. Importantly, a subsequent analysis on the same data demonstrated that cariprazine provides additional quality-adjusted life-years over 54 weeks compared with risperidone. ${ }^{64}$ These findings are important to demonstrate that the observed clinical changes on NS could be translated into meaningful improvements in the real world, also suggesting that cariprazine could be a good option for the treatment of predominant NS schizophrenia in the long term.

Two further small studies, reviewed in a single paper, ${ }^{53}$ may be mentioned since they showed a significant efficacy on NS that seems to be independent from secondary effects. The first study $(n=35)$ showed greater efficacy of olanzapine compared with haloperidol in reducing NS, while no differences were found with regard to depressive or positive symptoms. ${ }^{65}$ The second $(n=44)$ showed that quetiapine is more effective than risperidone on $\mathrm{NS}$, but not on positive symptoms. ${ }^{66}$

\section{Antidepressants}

Several clinical trials have suggested that the combined administration of an antipsychotic drug and an "add-on" antidepressant can improve NS and some affective disorders associated with schizophrenia, without exacerbating extrapyramidal side effects, in patients in whom such problems have proved persistent and who have been unresponsive to antipsychotic monotherapy. ${ }^{67-72}$

In 2016, Helfer and colleagues published a systematic review and meta-analysis of randomized controlled trials (RCTs) evaluating the efficacy of antidepressants added to antipsychotics. ${ }^{73}$ Despite the study inclusion criteria being broad, the authors conducted several subgroup analyses, including a metaanalysis of 10 trials providing data on the effects of antidepressants (fluoxetine, paroxetine, seligiline, citalopram, reboxetine, fluvoxamine, and mirtazapine) in schizophrenic patients with predominant NS. This subsample comprised 406 subjects overall and the metaanalysis showed that antidepressants were efficacious in reducing $\mathrm{NS}$, with one of the larger effect sizes
$(-0.53)$ among all subgroup analyses. ${ }^{73}$ Notably, eight of the 10 studies reviewed (256 patients overall) also analyzed the effect of antidepressants on depressive symptoms, showing a lower effect size $(-0.20)$, thus suggesting that the reduction in NS may be at least partly independent from the antidepressant effect. ${ }^{73}$

A previous meta-analysis of five RCTs testing the combination of an antidepressant (amitriptyline, mianserin hydrochloride, trazodone hydrochloride, paroxetine, fluoxetine, or fluvoxamine) added to antipsychotic medication against an antipsychotic alone for the treatment of NS in schizophrenia and/or schizophrenia-like psychoses included subjects suffering mainly from NS (meaning that studies enrolling patients with mainly positive symptoms and with a combination of negative and positive or negative and depressive symptoms were excluded). ${ }^{74}$ The results showed significant differences in favor of the combination therapy in core NS, with a medium to high effect size $(-0.71) .^{74}$

Further meta-analyses evaluated the use of antidepressants among subjects with schizophrenia. ${ }^{75,76}$ Despite generally reporting an effective response to antidepressive agents in treating NS with small to medium effect sizes, such studies often did not use a stringent definition of NS (eg, prominent/predominant NS) or control for potential antidepressant effects. Thus, effects on secondary NS, again, could not be ruled out. ${ }^{75,76}$

The mechanism by which adding an antidepressant to antipsychotic medication may cause a reduction in NS is still unclear. If a non-specific antidepressant effect cannot be excluded, it is also possible that the antidepressants' effectiveness may be influenced by the pharmacological action of the concurrent antipsychotic medication.

\section{A clinical algorithm for the treatment of NS}

According to the evidence discussed in the preceding sections and our clinical experience, we propose here a clinical algorithm for the management of NS in schizophrenic subjects (Figure 1).

The standard pharmacological treatment of schizophrenia is currently based on antipsychotic agents, on which most of the available literature is also focused. ${ }^{54}$ Among antipsychotics, amisulpride has been extensively evaluated and has demonstrated significant efficacy for predominant NS compared with placebo. ${ }^{57}$ However, 


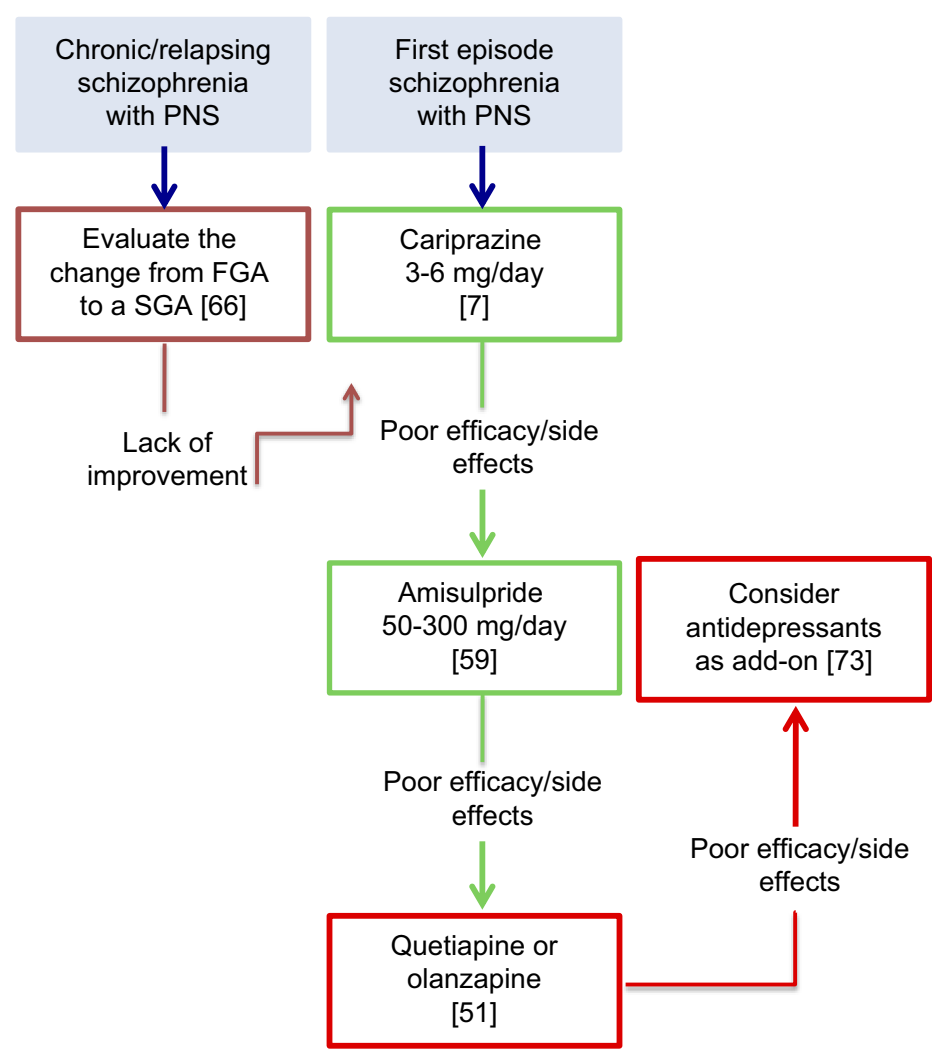

Figure I Clinical management of negative symptoms in schizophrenia.

Abbreviations: PNS, predominant negative symptoms; FGA, first-generation antipsychotic; SGA, second-generation antipsychotic.

given the pharmacological profile of amisulpride, its effect on NS is difficult to disentangle from that on depression. ${ }^{61}$ A single, though large, trial demonstrated a superiority of cariprazine compared with risperidone. ${ }^{7}$ Importantly, the study included patients with predominant NS, and effects on depressive symptoms, positive symptoms, and extrapyramidal side effects were controlled, providing a larger guarantee against the confounding effect on secondary NS. Thus, we can suggest the use of cariprazine as a first-line pharmacological treatment in schizophrenia with predominant NS. According to the product label, the daily dose of cariprazine should range between 3 and $6 \mathrm{mg} .{ }^{77}$ In the study conducted on patients with predominant NS, the target dose was $4.5 \mathrm{mg}$ per day. ${ }^{7}$ Importantly, given the long half-life of cariprazine (1-3 weeks), many weeks are needed to achieve a steady state after each dosage increment and prior to evaluating treatment effectiveness. When cariprazine fails owing to poor efficacy or side effects (the most common adverse events being insomnia, akathisia, headache, and anxiety ${ }^{7}$ ), amisulpride should be considered. Clinical trials evaluating the efficacy of amisulpride on NS used daily doses ranging from 50 to $300 \mathrm{mg}$ (with most of the included patients being administered $100 \mathrm{mg}$ per day). ${ }^{57}$ Therefore, while amisulpride can be increased up to $1,200 \mathrm{mg}$ per day in individual cases, a low dosage (50-300 $\mathrm{mg}$ ) is recommended for schizophrenic patients characterized by predominant NS. While there is general agreement that SGAs should be preferred over FGAs, few data are available for specific SGAs aside from the two studies mentioned above ${ }^{7,57}$. When both cariprazine and amisulpride have been shown to fail, olanzapine and quetiapine could be used. This suggestion is based on the results of the meta-analysis by Krause et $\mathrm{al}^{53}{ }^{53}$ in which olanzapine and quetiapine proved to be the most effective drugs on schizophrenia NS after amisulpride and cariprazine. In detail, olanzapine was similar to amisulpride and superior to alloperidol, whereas quetiapine was similar to olanzapine and superior to risperidone.

Furthermore, although the available information is currently too limited to allow any firm conclusions to be drawn, the add-on therapy with antidepressants to antipsychotics could be reasonably considered as a further choice for NS in schizophrenia. ${ }^{53}$ 


\section{Challenges and strategies in the treatment of schizophrenia with persistent NS}

Despite our growing understanding of schizophrenia, there is a lack of treatments targeting its whole multifaceted phenotype, involving thought, perception, cognition, and emotion. All currently approved medications for schizophrenia act via dopamine modulation, mostly targeting positive symptoms, agitation, and aggression, while the functionally important domains of NS and cognitive dysfunction remain relatively unaddressed.

This prompted the search for extra-dopaminergic neurotransmitter modulation to address not only positive symptoms, but also other domains of schizophrenia. ${ }^{42,78}$ However, most of the agents developed in the past few decades still have a limited efficacy on NS, suggesting an urgent need for specific treatments for this neglected domain. ${ }^{79,80}$ On one hand, NS have been found to improve in psychosocial and pharmacological interventions for psychosis that were not aimed primarily at $\mathrm{NS} ;{ }^{81}$ on the other hand, RCTs that focused primarily on NS using intensive treatments in preselected samples have not produced strong effects. ${ }^{76}$ This may indicate that the effects emerging from other groups of patients cannot be readily generalized to low-functioning subjects with moderate to severe NS and that more effective interventions await to be developed for this population. This also illustrates the heterogeneity in treatment response. Another challenging aspect of NS treatment is that changes in NS may be difficult to detect in a clinical setting. This is due not only to measurement issues, but also to the fact that once brain functioning has been ameliorated, it may take time for this to translate into behavioral change.

A further issue is that approved antipsychotics have been tested in patients diagnosed on the basis of the unitary concept of schizophrenia, as opposed to the hypothesis of distinct subtypes of the disease, each one requiring specific drug profiles beyond $\mathrm{D}_{2}$ receptor antagonism. A related question, which could impact on the future pharmacotherapy of schizophrenia, is whether we should aim to use only one treatment addressing all dimensions of schizophrenia, or rely on drug combinations to target multiple phenotypes and symptom domains. The latter approach is already applied in other complex and chronic diseases (ie, in oncology, cardiology and psychiatry), but is should be approached carefully considering the increased risks of side effects associated with polypharmacy. ${ }^{82}$

\section{Conclusion}

So far, only a few treatments for schizophrenia NS have been tested, showing only modest results. The lack of a shared definition of NS among pharmaceutical regulatory agencies, as well as among researchers, contributes to the inconsistency in inclusion criteria of the existing clinical trials, reducing the chance of drawing solid conclusions. Cariprazine was shown to be effective in preclinical models of anhedonia, and more effective than risperidone in schizophrenic subjects with predominant $\mathrm{NS},{ }^{7}$ opening a new, promising avenue of intervention for NS. Still, further trials are urgently needed to update current knowledge on the treatment of NS, along with stronger efforts in drug discovery and development.

\section{Acknowledgments}

Editorial assistance was provided by Luca Giacomelli, $\mathrm{PhD}$, Ambra Corti, and Aashni Shah, of Polistudium (Milan, Italy); this assistance was supported by Recordati.

\section{Disclosure}

Dr Giancarlo Cerveri reports grants from Recordati SpA during the conduct of the study. The authors report no other conflicts of interest in this work.

\section{References}

1. National Institute of Mental Health. Schizophrenia. Last Revised 2016 Feb; NIH publication no. 15-3517; 2009. Avialable from: www.nimh. nih.gov/health/publications/schizophrenia-booklet/index.shtml Accessed Jul 31, 2018

2. Burton N. Living with Schizophrenia. Oxford: Acheron Press; 2012: P20.

3. Kirkpatrick B, Fenton WS, Carpenter WT Jr, et al. The NIMH-MATRICS consensus statement on negative symptoms. Schizophr Bull. 2006;32(2):214-219. doi:10.1093/schbul/sbj053

4. Blanchard JJ, Kring AM, Horan WP, et al. Toward the next generation of negative symptom assessments: the collaboration to advance negative symptom assessment in schizophrenia. Schizophr Bull. 2011;37 (2):291-299. doi:10.1093/schbul/sbq104

5. Leucht S, Davis JM. Schizophrenia, primary negative symptoms, and soft outcomes in psychiatry. Lancet. 2017;389(10074):1077-1078. doi:10.1016/S0140-6736(17)30181-2

6. Hunter R, Barry S. Negative symptoms and psychosocial functioning in schizophrenia: neglected but important targets for treatment. Eur Psychiatry. 2012;27(6):432-436. doi:10.1016/j.eurpsy.2011.02.015

7. Németh G, Laszlovszky I, Czobor P, et al. Cariprazine versus risperidone monotherapy for treatment of predominant negative symptoms in patients with schizophrenia: a randomised, double-blind, controlled trial. Lancet. 2017;389(10074):1103-1113. doi:10.1016/S0140-6736(17)30060-0

8. National Institute for Health and Care Excellence. Psychosis and schizophrenia in adults: prevention and management (CG178); 2014. Available from: http://www.nice.org.uk (Accessed 28 Apr 2017).

9. Corponi F, Serretti A, Montgomery S, Fabbri C. Cariprazine specificity profile in the treatment of acute schizophrenia: a meta-analysis and meta-regression of randomized-controlled trials. Int Clin Psychopharmacol. 2017;32(6):309-318. 
10. Jackson JH. On temporary mental disorders after epileptic paroxysms. West Riding Lunatic Asylum Med Rep. 1885;5:105-29.

11. Kraepelin E. Dementia Praecox and Paraphrenia. New York: Huntington; 1919.

12. Bleuler E. Dementia Praecox, or the Group of Schizophrenias. New York: International Universities Press; 1950.

13. Foussias G, Remington G. Negative symptoms in schizophrenia: avolition and Occam's razor. Schizophr Bull. 2010;36(2):359-369. doi:10.1093/schbul/sbn094

14. Malaspina D, Walsh-Messinger J, Gaebel W, et al. Negative symptoms, past and present: a historical perspective and moving to DSM-5. Eur Neuropsychopharmacol. 2014;24(5):710-724. doi:10.1016/j.euroneuro.2013.10.018

15. American Psychiatric Association. Diagnostic and Statistical Manual of Mental Disorders. 3rd ed. Washington, DC: Author; 1980.

16. Schneider K. Clinical Psychopathology. New York: Grune and Stratton; 1959.

17. Crow TJ. Molecular pathology of schizophrenia: more than one disease process? Bmj. 1980;280(7):66-68. doi:10.1136/ bmj.280.6207.66

18. Andreasen NC, Olsen S. Negative v positive schizophrenia. Definition and validation. Arch Gen Psychiatry. 1982;39:789-794.

19. Peralta V, de Leon J, Cuesta MJ. Are there more than two syndromes in schizophrenia? A critique of the positive-negative dichotomy. $\mathrm{Br}$ J Psychiatry. 1992;161:335-343.

20. Galderisi S, Mucci A, Bitter I, Libiger J, Bucci P, Fleischhacker WW, Eufest Study Group. Persistent negative symptoms in first episode patients with schizophrenia: results from the European first episode schizophrenia trial. Eur Neuropsychopharmacol. 2013;23 (3):196-204. doi:10.1016/j.euroneuro.2012.04.019

21. Carpenter WT. The deficit syndrome. Am $J$ Psychiatry. 1994;151:327-329. doi:10.1176/ajp.151.3.327

22. Kirkpatrick B, Mucci A, Galderisi S. Primary, enduring negative symptoms: an update on research. Schizophr Bull. 2017;43 (4):730-736. doi:10.1093/schbul/sbx064

23. American Psychiatric Association. Diagnostic and Statistical Manual of Mental Disorders. 5th ed. Washington, DC: Author; 2013.

24. World Health Organization. The ICD-10 Classification of Mental and Behavioural Disorders: Clinical Descriptions and Diagnostic Guidelines. Geneva: World Health Organization; 1992.

25. Tandon R, Gaebel W, Barch DM, et al. Definition and description of schizophrenia in the DSM-5. Schizophr Res. 2013;150(1):3-10. doi:10.1016/j.schres.2013.05.028

26. Davis MC, Horan WP, Marder SR. Psychopharmacology of the negative symptoms: current status and prospects for progress. Eur Neuropsychopharmacol. 2014;24:788-799. doi:10.1016/j. euroneuro.2013.10.010

27. Garay RP, Citrome L, Samalin L, et al. Therapeutic improvements expected in the near future for schizophrenia and schizoaffective disorder: an appraisal of phase III clinical trials of schizophrenia-targeted therapies as found in US and EU clinical trial registries. Expert Opin Pharmacother. 2016;19:1-16.

28. Kirkpatrick B, Strauss GP, Nguyen L, et al. The brief negative symptom scale: psychometric properties. Schizophr Bull. 2011;37 (2):300-305. doi:10.1093/schbul/sbq059

29. Ahmed AO, Strauss GP, Buchanan RW, Kirkpatrick B Carpenter WT. Are negative symptoms dimensional or categorical? Detection and validation of de cit schizo-phrenia with taxometric and latent variable mixture models. Schizophr Bull. 2015;41:879-891. doi:10.1093/schbul/sbt194

30. Barry SJ, Gaughan TM, Hunter R. Schizophrenia. BMJ Clin Evid. 2012;2012:pii: 1007.

31. Gillespie AL, Samanaite R, Mill J, Egerton A, MacCabe JH. Is treatment-resistant schizophrenia categorically distinct from treatment-responsive schizophrenia? A systematic review. BMC Psychiatry. 2017;17:12. doi:10.1186/s12888-017-1489-6
32. Bertelsen M, Jeppesen P, Petersen L, et al. Course of illness in a sample of 265 patients with first-episode psychosis-five-year follow-up of the Danish OPUS trial. Schizophr Res. 2009;107(2-3):173-178. doi:10.1016/j.schres.2008.09.018

33. Levine SZ, Leucht S. Attaining and sustaining remission of predominant negative symptoms. Schizophr Res. 2013;143(1):60-64. doi:10.1016/j.schres.2012.11.010

34. Schennach-Wolff R, Jäger M, Mayr A, et al. Predictors of response and remission in the acute treatment of first-episode schizophrenia patients-is it all about early response? Eur Neuropsychopharmacol. 2011;21(5):370-378. doi:10.1016/j.euroneuro.2010.10.003

35. Best MW, Grossman M, Oyewumi LK, Bowie CR. Examination of the positive and negative syndrome scale factor structure and longitudinal relationships with functioning in early psychosis. Early Interv Psychiatry. 2016;10(2):165-170. doi:10.1111/eip.12190

36. Rabinowitz J, Levine SZ, Garibaldi G, Bugarski-Kirola D, Berardo CG, Kapur S. Negative symptoms have greater impact on functioning than positive symptoms in schizophrenia: analysis of CATIE data. Schizophr Res. 2012;137(1-3):147-150. doi:10.1016/j. schres.2012.01.015

37. Cacciotti-Saija C, Langdon R, Ward PB, Hickie IB, Guastella AJ. Clinical symptoms predict concurrent social and global functioning in an early psychosis sample. Early Interv Psychiatry. 2015;12 (2):177-184. doi:10.1111/eip.12295

38. Downs J, Dean H, Lechler S, et al. Negative symptoms in early-onset psychosis and their association with antipsychotic treatment failure. Schizophr Bull. 2019;45(1):69-79. doi:10.1093/ schbul/sbx 197

39. Ventura J, Subotnik KL, Gitlin MJ, et al. Negative symptoms and functioning during the first year after a recent onset of schizophrenia and 8 years later. Schizophr Res. 2015;161(2-3):407-413. doi:10.1016/j.schres.2014.10.043

40. Hovington CL, Bodnar M, Joober R, Malla AK, Lepage M. Impairment in verbal memory observed in first episode psychosis patients with persistent negative symptoms. Schizophr Res. 2013;147 (2-3):223-229. doi:10.1016/j.schres.2013.04.006

41. Carpenter WT Jr, Heinrichs DW, Wagman AM. Deficit and nondeficit forms of schizophrenia: the concept. Am J Psychiatry. 1988;145 (5):578-583. doi:10.1176/ajp.145.5.578

42. Carbon M, Correll CU. Thinking and acting beyond the positive: the role of the cognitive and negative symptoms in schizophrenia. CNS Spectr. 2014;19(Suppl 1):38-52. quiz 35-7, 53. DOI:10.1017/ S1092852914000601

43. Galderisi S, Quarantelli M, Volpe U, et al. Patterns of structural MRI abnormalities in deficit and nondeficit schizophrenia. Schizophr Bull. 2008;34(2):393-401. doi:10.1093/schbul/sbm097

44. Kirkpatrick B, Progress in the study of negative symptoms. Schizophr Bull. 2014;Suppl 2:S101-S106. doi:10.1093/schbul/sbt158

45. Kirkpatrick B, Galderisi S. Deficit schizophrenia: an update. World Psychiatry. 2008;7:143-147. doi:10.1002/wps.2008.7.issue-3

46. Buchanan RW. Persistent negative symptoms in schizophrenia: an overview. Schizophr Bull. 2007;33:1013-1022. doi:10.1093/schbul/sb1057

47. Galderisi S, Maj M, Mucci A, et al. Historical, psychopathological, neurological, and neuropsychological aspects of deficit schizophrenia: a multicenter study. Am J Psychiatry. 2002;159(6):983-990. doi:10.1176/appi.ajp.159.6.983

48. Kay SR, Fiszbein A, Opler LA. The positive and negative syndrome scale (PANSS) for schizophrenia. Schizophr Bull. 1987;13(2):261-276.

49. Buchanan RW, Panagides J, Zhao J, et al. Asenapine versus olanzapine in people with persistent negative symptoms of schizophrenia. $J$ Clin Psychopharmacol. 2012;32(1):36-45. doi:10.1097/ JCP.0b013e31823f880a

50. Stauffer VL, Song G, Kinon BJ, et al. Responses to antipsychotic therapy among patients with schizophrenia or schizoaffective disorder and either predominant or prominent negative symptoms. Schizophr Res. 2012;134:195-201. doi:10.1016/j.schres.2011.09.028 
51. Alphs L, Panagides J, Lancaster S. Asenapine in the treatment of negative symptoms of schizophrenia: clinical trial design and rationale. Psychopharmacol Bull. 2007;40:41-53.

52. Marder SR, Alphs L, Anghelescu I-G, et al. Issues and perspectives in designing clinical trials for negative symptoms in schizophrenia. Schizophr Res. 2013;150(2-3):328-333. doi:10.1016/j. schres.2013.07.058

53. Krause M, Zhu Y, Huhn M, et al. Antipsychotic drugs for patients with schizophrenia and predominant or prominent negative symptoms: a systematic review and meta-analysis. Eur Arch Psychiatry Clin Neurosci. 2018;268(7):625-639. doi:10.1007/s00406-018-0869-3

54. Tandon R. Antipsychotics in the treatment of schizophrenia: an overview. $J$ Clin Psychiatry. 2011;72:4-8. doi:10.4088/ JCP.10075su1.01

55. Solmi M, Murru A, Pacchiarotti I, et al. Safety, tolerability, and risks associated with first- and second-generation antipsychotics: a state-of-the-art clinical review. Ther Clin Risk Manag. 2017;13:757-777. doi:10.2147/TCRM.S117321

56. Leucht S, Corves C, Arbter D, Engel RR, Li C, Davis JM. Secondgeneration versus first-generation antipsychotic drugs for schizophrenia: a meta-analysis. Lancet. 2009;373(9657):31-41. doi:10.1016/ S0140-6736(08)61764-X

57. Leucht S. Amisulpride a selective dopamine antagonist and atypical antipsychotic: results of a meta-analysis of randomized controlled trials. Int $J$ Neuropsychopharmacol. 2004;7(1):S15-S20. doi: $10.1017 / \mathrm{S} 1461145704004109$

58. Kumar S, Chaudhury S. Efficacy of amisulpride and olanzapine for negative symptoms and cognitive impairments: an open-label clinical study. Ind Psychiatry J. 2014;23(1):27-35. doi:10.4103/09726748.144953

59. Levine SZ, Leucht S. Treatment response heterogeneity in the predominant negative symptoms of schizophrenia: analysis of amisulpride vs placebo in three clinical trials. Schizophr Res. 2014;156 (1):107-114. doi:10.1016/j.schres.2014.04.005

60. Möller HJ. Amisulpride: efficacy in the management of chronic patients with predominant negative symptoms of schizophrenia. Eur Arch Psychiatry Clin Neurosci. 2001;251(5):217-224.

61. Pani L, Gessa G. The substituted benzamides and their clinical potential on dysthymia and on the negative symptoms of schizophrenia. Mol Psychiatry. 2002;7:247-253. doi:10.1038/sj.mp.4001040

62. Citrome L. Cariprazine for acute and maintenance treatment of adults with schizophrenia: an evidence-based review and place in therapy. Neuropsychiatr Dis Treat. 2018;14:2563-2577. doi:10.2147/NDT.S159704

63. Citrome L. Cariprazine: chemistry, pharmacodynamics, pharmacokinetics, and metabolism, clinical efficacy, safety, and tolerability. Expert Opin Drug Metab Toxicol. 2013;9(2):193-206. doi:10.1517/ 17425255.2013.759211

64. Németh B, Molnár A, Akehurst R, et al. Quality-adjusted life year difference in patients with predominant negative symptoms of schizophrenia treated with cariprazine and risperidone. J Comp Eff Res. 2017;6(8):639-648. doi:10.2217/cer-2017-0024

65. Lindenmayer JP, Khan A, Iskander A, et al. A randomized controlled trial of olanzapine versus haloperidol in the treatment of primary negative symptoms and neurocognitive deficits in schizophrenia. $J$ Clin Psychiatry. 2007;68(3):368-379. doi:10.4088/JCP.v68n0303

66. Riedel M, Muller N, Strassnig M, et al. Quetiapine has equivalent efficacy and superior tolerability to risperidone in the treatment of schizophrenia with predominantly negative symptoms. Eur Arch Psychiatry Clin Neurosci. 2005;255(6):432-437. doi:10.1007/s00406-005-0622-6
67. Silver H, Nassar A. Fluvoxamine improves negative symptoms in treated chronic schizophrenia: an add-on double-blind, placebo-controlled study. Biol Psychiatry. 1992;31:698-704. doi:10.1016/0006-3223(92)90279-9

68. Spina E, De Domenico P, Ruello C, et al. Adjunctive fluoxetine in the treatment of negative symptoms in chronic schizophrenic patients. Int Clin Psychopharmacol. 1994;9:281-285. doi:10.1097/00004850199400940-00007

69. Goff DC, Midha KK, Sarid-Segal O, Hubbard JW, Amico E. A placebo-controlled trial of fluoxetine added to neuroleptic in patients with schizophrenia. Psychopharmacology. 1995;117:417-423. doi:10.1007/BF02246213

70. Salokangas RK, Saarijärvi S, Taiminen T, et al. Citalopram as an adjuvant in chronic schizophrenia: a double-blind placebo-controlled study. Acta Psychiatr Scand. 1996;94:175-180. doi:10.1111/j.1600-0447.1996. tb09844.x

71. Taiminen TJ, Syvälahti E, Saarijärvi S, et al. Citalopram as an adjuvant in schizophrenia: further evidence for a serotonergic dimension in schizophrenia. Int Clin Psychopharmacol. 1997;12:31-35. doi:10.1097/00004850-199701000-00004

72. Jockers-Scherübl MC, Bauer A, Godemann F, Reischies FM, Selig F, Schlattmann P. Negative symptoms of schizophrenia are improved by the addition of paroxetine to neuroleptics. Int Clin Psychopharmacol. 2005;20:27-31. doi:10.1097/00004850-200501000-00006

73. Helfer B, Samara MT, Huhn M, et al. Efficacy and safety of antidepressants added to antipsychotics for schizophrenia: a systematic review and meta-analysis. Am J Psychiatry. 2016;173(9):876-886. doi:10.1176/appi.ajp.2016.15081035

74. Rummel C, Kissling W, Leucht S. Antidepressants as add-on treatment to antipsychotics for people with schizophrenia and pronounced negative symptoms: a systematic review of randomized trials. Schizophr Res. 2005;80(1):85-97. doi:10.1016/j. schres.2005.07.035

75. Singh SP, Singh V, Kar N, Chan K. Efficacy of antidepressants in treating the negative symptoms of chronic schizophrenia: meta-analysis. Br J Psychiatry. 2010;197(3):174-179. doi:10.1192/ bjp.bp. 109.067710

76. Fusar-Poli P, Papanastasiou E, Stahl D, et al. Treatments of negative symptoms in schizophrenia: meta-analysis of 168 randomized placebo-controlled trials. Schizophr Bull. 2015;41(4):892-899. doi: $10.1093 / \mathrm{schbul} / \mathrm{sbu} 170$

77. Cariprazine Summary of Product Characteristics. Available from: https://www.ema.europa.eu/en/documents/product-information/rea gila-epar-product-information_en.pdf. Accessed May 20, 2019.

78. Carlsson A, Carlsson ML. A dopaminergic deficit hypoth- esis of schizophrenia: the path to discovery. Dialogues Clin Neurosci. 2006;8:137-142.

79. Seeman P, Lee T. Antipsychotic drugs: direct correlation between clinical potency and presynaptic action on dopamine neurons. Science. 1975;188:1217-1219. doi:10.1126/science.1145194

80. Leucht S, Cipriani A, Spineli L, et al. Comparative efficacy and tolerability of 15 antipsychotic drugs in schizophrenia: a multiple-treatments meta-analysis. Lancet. 2013;382 (9896):951-962. doi:10.1016/S0140-6736(13)60733-3

81. Elis O, Caponigro JM, Kring AM. Psychosocial treatments for negative symptoms in schizophrenia: current practices and future directions. Clin Psychol Rev. 2013;33(8):914-928. doi:10.1016/j.cpr.2013.07.001

82. Peters JU. Polypharmacology—foe or friend? J Med Chem. 2013;56:8955-8971. 


\section{Publish your work in this journal}

Neuropsychiatric Disease and Treatment is an international, peerreviewed journal of clinical therapeutics and pharmacology focusing on concise rapid reporting of clinical or pre-clinical studies on a range of neuropsychiatric and neurological disorders. This journal is indexed on PubMed Central, the 'PsycINFO' database and CAS, and is the official journal of The International Neuropsychiatric Association (INA). The manuscript management system is completely online and includes a very quick and fair peer-review system, which is all easy to use. Visit http://www.dovepress.com/testimonials.php to read real quotes from published authors.

Submit your manuscript here: https://www.dovepress.com/neuropsychiatric-disease-and-treatment-journal 